\title{
Impact of Radiotherapy, Chemotherapy and Surgery in Multimodal Treatment of Locally Advanced Esophageal Cancer
}

\author{
Bernhard Berger ${ }^{a}$ Katharina Stahlberg ${ }^{a}$ Annina Lemminger ${ }^{a}$ Martin Bleif ${ }^{a}$ \\ Claus Belka ${ }^{b}$ Michael Bamberg ${ }^{a}$ \\ ${ }^{a}$ Department of Radiation Oncology, University of Tuebingen, Tuebingen, and ${ }^{\mathrm{b}}$ Department of Radiation Oncology, \\ University of Munich, Munich, Germany
}

\section{Key Words}

Esophageal cancer $\cdot$ Chemoradiation •

Radiochemotherapy $\cdot$ Radiotherapy $\cdot$ Surgery

\begin{abstract}
Objectives: It was the aim of this study to assess our institutional experience with definitive chemoradiation (CRT) versus induction chemotherapy followed by CRT with or without surgery (C-CRT/S) in esophageal cancer. Methods: We retrospectively analyzed 129 institutional patients with locally advanced esophageal cancer who had been treated by either CRT in analogy to the RTOG 8501 trial $(n=78)$ or CCRT/S ( $n=51)$. Results: The median, 2- and 5-year overall survival (OS) of the entire collective was 17.6 months, 42 and $24 \%$, respectively, without a significant difference between the CRT and C-CRT/S groups. In C-CRT/S patients, surgery statistically improved the locoregional control (LRC) rates (2-year LRC 73.6 vs. $21.2 \% ; p=0.003$ ); however, this was translated only into a trend towards improved OS ( $p=0.084)$. The impact of escalated radiation doses ( $\geq 60.0 \mathrm{vs} .<60.0 \mathrm{~Gy}$ ) on LRC was detectable only in T1-3 N0-1 M0 patients of the CRT group (2-year LRC 77.8 vs. $42.3 \% ; p=0.036$ ). Conclusion: Definitive CRT and a trimodality approach including surgery (C-CRT/S) had a comparable outcome in this unselected pa-
\end{abstract}

tient collective. Surgery and higher radiation doses improve LRC rates in subgroups of patients, respectively, but without effect on OS.

Copyright $\odot 2012$ S. Karger AG, Basel

\section{Introduction}

Almost 20 years ago, the Radiation Therapy Oncology Group (RTOG) 8501 trial defined concomitant chemoradiation (CRT) as the standard of care for locally advanced esophageal cancer [1-3]. Patients treated with 50.0 Gy concurrently with two parallel and two adjuvant cycles of cisplatin and 5-fluorouracil (5-FU) reached a 26\% 5-year overall survival (OS) [2]. Since then, technical and procedural treatment options have considerably evolved $[4,5]$. However, the results of the original RTOG trial (arm B) have not been prospectively exceeded, and today, the optimal arrangement of CRT remains debatable.

Particular uncertainty concerns the optimal radiation (RT) dose within the concept of definitive CRT. Although the INT 0123 trial did not provide evidence of survival benefits by a boost dose to 64.8 Gy versus standard 50.4 Gy [6], today, most centers routinely escalate the doses to $>50.0$ Gy. Accordingly, prospective trials on definitive 
versus neoadjuvant CRT have shown the safety of $\geq 60.0$ Gy during definitive CRT $[7,8]$. However, a standardized dose escalation during RTOG 8501 analog CRT has not been validated so far.

If surgery is included into a multimodal approach to esophageal cancer, the variability of treatment options is even higher. Neoadjuvant CRT followed by surgery (trimodality treatment) has been randomized prospectively against definitive CRT in at least two large trials $[7,8]$. Although differing in treatment schedule and design, both studies confirmed the lack of a survival benefit by surgery, particularly in patients who respond to induction CRT. The inclusion of surgery led to improved locoregional control (LRC) rates; however, perioperative morbidity hampered its translation into improved OS. Thus, as a matter of principle, a non-surgical approach to esophageal cancer is not inferior to trimodality treatment $[4,9]$.

The CRT regimen applied in the two above-mentioned trials $[7,8]$ differed from the standard as set by arm B of the RTOG 8501 study: whereas RT was mainly performed as split-course hypofractionated treatment in the French study $(2 \times 15.0$ Gy) [7], the German trial scheduled induction chemotherapy with cisplatin, etoposide and 5-FU followed by CRT in standard fractionation (40.0 Gy) concomitant to cisplatin and etoposide [8]. Likewise, several institutional reviews reported on differing CRT regimens with or without surgery [10-12].

In light of the broad spectrum of CRT regimens used for multimodal treatment of esophageal cancer, we retrospectively analyzed our own institutional experience which was rather strictly oriented towards the concept of the RTOG 8501 trial (CRT group) and the German phase III trial on trimodality treatment versus definitive CRT (C-CRT/S group), respectively [8].

\section{Patients and Methods}

\section{Treatment Protocol}

Between 1999 and 2009, 149 patients with primary or recurrent non-metastatic esophageal cancer underwent treatment at the Department of Radiation Oncology, University of Tübingen. The present analysis was limited to patients who received definitive CRT (CRT group, $\mathrm{n}=78$ ) or inductive chemotherapy followed by CRT with or without surgery (C-CRT/S group, $n=51$ ). All patients had a biopsy-proven squamous cell carcinoma or adenocarcinoma of the cervical, thoracic or distal esophagus classified as T1-4 N0-1 M0-1a according to the 6.0 TNM criteria. A total of 129 patients met the research criteria and were systematically reviewed for the following data: patient demographics, tumor stage, histology, treatment details and performance, toxicity, treatment outcome and follow-up.
Definitive CRT was performed according to arm B of the RTOG 8501 trial [1] delivering 50.0 Gy with two concomitant and two adjuvant cycles of cisplatin $\left(75 \mathrm{mg} / \mathrm{m}^{2}\right.$ on day 1) and 5 -FU $\left(1,000 \mathrm{mg} / \mathrm{m}^{2}\right.$ on days $\left.1-4\right)$. However, in contrast to the $50.0-\mathrm{Gy}$ end dose of the RTOG trial, the RT doses were individually escalated in most patients with respect to tumor localization and size, patient performance and treatment tolerability (median boost dose 10.0 Gy). For RT, we routinely used a computed tomographybased 3D conformal technique or intensity-modulated radiotherapy. The target volume delineation was based on the International Commission on Radiation Units and Measurements 50 definitions and followed the treatment conditions of contemporary trials on esophageal cancer $[6,8,13]$.

Trimodality treatment (C-CRT/S) was analogized to the German multicenter trial on neoadjuvant chemotherapy/CRT plus surgery versus definitive CRT, with 10 of 51 patients being randomized in the original study [8]. Treatment consisted of inductive chemotherapy with three courses of cisplatin, etoposide and 5-FU/leucovorin, followed by CRT (30.0-40.0 Gy with concomitant cisplatin on days 2 and 8, etoposide on days 3-5). After restaging, the patients were allocated individually to either surgery or boost RT (60.0 - to 65.0-Gy end dose) reflecting the initial tumor localization and size (surgical accessability), the restaging results, medical fitness and the patient's preference.

\section{Statictical Analysis}

The main endpoint of this intent-to-treat analysis was to determine OS, LRC and distant control (DC) rates. The survival outcome was calculated using the Kaplan-Meier method with OS, LRC and DC being assessed from the first day of treatment until locoregional recurrence or progress, appearance of distant metastases, and death from any cause, respectively. To compare survival data, the Mantel-Cox log-rank test was used ( $\mathrm{p}$ values $\leq 0.05$ were considered significant). Patient and treatment characteristics were compared using a two-sided Mann-Whitney U test for continuous variables and Fisher's exact test for categorical variables, respectively. Secondary objectives of this analysis were response and toxicity evaluation as well as identification of pretreatment and treatment-related prognostic factors. The treatment outcome was assessed according to the Response Evaluation Criteria in Solid Tumors (RECIST) by endoscopy and CT scans immediately after the end of neoadjuvant CRT (C-CRT/S group) or 3 months after definitive CRT (CRT group). Treatment-related toxicities were scored according to the Common Terminology Criteria for Adverse Events (version 3.0). To assess the prognostic impact of patient and treatment characteristics, the Cox proportional hazards model was used. Factors proven to be of significance ( $\mathrm{p} \leq 0.05$ ) were entered into the multivariate analysis. All data were analyzed using PASW 18.0 (SPSS Inc., Chicago, Ill., USA).

\section{Results}

\section{Patient and Treatment Characteristics}

Of 129 patients included in this analysis, 78 patients (60\%) received CRT whereas 51 patients (40\%) underwent C-CRT/S. Patient demographics are listed in table 1. An intercohort comparison revealed no relevant differences 
Table 1. Patient characteristics

\begin{tabular}{|c|c|c|c|}
\hline & $\begin{array}{l}\text { CRT } \\
(\mathrm{n}=78)\end{array}$ & $\begin{array}{l}\text { C-CRT/S } \\
(\mathrm{n}=51)\end{array}$ & $\begin{array}{l}\text { Entire cohort } \\
(\mathrm{n}=129)\end{array}$ \\
\hline Median age, years & $63[43-78]$ & $60[42-76]$ & $62[42-78]$ \\
\hline \multicolumn{4}{|l|}{ Age } \\
\hline$\leq 60$ years & $32(41)$ & $24(47)$ & $56(43)$ \\
\hline$>60$ years & $46(59)$ & $27(53)$ & $73(57)$ \\
\hline \multicolumn{4}{|l|}{ Gender } \\
\hline Male & $68(87)$ & $43(84)$ & $111(86)$ \\
\hline Female & $10(13)$ & $8(16)$ & $18(14)$ \\
\hline \multicolumn{4}{|l|}{ Histology } \\
\hline SCC & $61(78)$ & $36(71)$ & $97(75)$ \\
\hline $\mathrm{AC}$ & $15(19)$ & $15(29)$ & $30(23)$ \\
\hline Missing & $2(3)$ & & $2(2)$ \\
\hline \multicolumn{4}{|l|}{ Grading } \\
\hline G1 & $7(9)$ & $5(10)$ & $12(9)$ \\
\hline G2 & $39(46)$ & $30(59)$ & $69(53)$ \\
\hline G3 & $22(28)$ & $14(27)$ & $36(28)$ \\
\hline Missing & $10(13)$ & $2(4)$ & $12(9)$ \\
\hline \multicolumn{4}{|l|}{ Primary tumor subsite } \\
\hline Proximal third & $19(24)$ & $9(18)$ & $28(22)$ \\
\hline Mid third & $32(41)$ & $21(41)$ & $53(41)$ \\
\hline Distal third & $21(27)$ & $14(27)$ & $35(27)$ \\
\hline GEJ & $6(8)$ & $7(14)$ & $13(10)$ \\
\hline \multicolumn{4}{|l|}{ Tumor status } \\
\hline Tx (nodal recurrence) & $4(5)$ & & $4(3)$ \\
\hline $\mathrm{T} 1$ & $4(5)$ & & $4(3)$ \\
\hline $\mathrm{T} 2$ & $7(9)$ & $2(4)$ & $9(7)$ \\
\hline T3 & $48(62)$ & $47(92)$ & $95(74)$ \\
\hline $\mathrm{T} 4(\mathrm{p}=0.008)$ & $15(19)$ & $2(4)$ & $17(13)$ \\
\hline \multicolumn{4}{|l|}{ Nodal status } \\
\hline No & $19(24)$ & $8(16)$ & $27(21)$ \\
\hline N1 & $59(76)$ & $43(84)$ & $102(79)$ \\
\hline \multicolumn{4}{|l|}{ Stage } \\
\hline I/II & $23(29)$ & $10(20)$ & $33(26)$ \\
\hline III & $49(63)$ & $40(78)$ & $89(69)$ \\
\hline IVA & $6(8)$ & $1(2)$ & $7(5)$ \\
\hline
\end{tabular}

Figures in parentheses are percentages; figures in brackets are ranges. SCC = Squamous cell carcinoma; $\mathrm{AC}=$ adenocarcinoma; GEJ = gastroesophageal junction.

except for a higher frequency of T4 tumors in the CRT group ( 19 vs. $4 \% ; \mathrm{p}=0.008$ ). Corresponding to the higher frequency of obstructive tumors in the CRT group, more patients were dependent on feeding tubes before treatment ( 27 vs. $10 \% ; \mathrm{p}=0.024$ ). The treatment differences between the two groups are shown in table 2. According to the differing treatment intention, patients in the CRT group received significantly higher RT doses (median RT dose 60.0 vs. $40.0 \mathrm{~Gy}$; $<<0.001$ ) and had greater planning target volumes (median 842 vs. $706 \mathrm{ml} ; \mathrm{p}<0.001$ ).

\section{Treatment Performance and Tolerability}

All patients scheduled for CRT received the RT dose as planned. In contrast, chemotherapy had to be modified or even aborted in about one third of patients $(n=28)$ due to non-specific deterioration of performance status ( $\mathrm{n}=$ $10)$, hematological toxicity $(n=7)$ or denial of further treatment $(n=8)$. In the C-CRT/S group, the RT dose was limited to 36.0 Gy without chemotherapy due to progressive disease in 1 patient scheduled for $40.0 \mathrm{~Gy}$. With respect to chemotherapy, at least two inductive cycles were accomplished by all patients. Grade 3/4 hematological side effects required dose reductions during the following courses in 9 patients. Five patients proceeded with RT alone instead of concomitant CRT due to progressive disease $(\mathrm{n}=2)$, acute renal failure $(\mathrm{n}=1)$ and hematological toxicity $(\mathrm{n}=2)$. Fifty-seven patients $(73 \%)$ in the CRT group and 49 patients (96\%) in the C-CRT/S group received more than two thirds of the chemotherapy as planned (table 2). Among the 51 patients of the C-CRT/S group, 28 patients were scheduled for surgery. However, at the time of surgery, 9 patients were found to be irresectable or showed loss of distant tumor control; the remain$\operatorname{der}(\mathrm{n}=19)$ received a complete tumor resection $(\mathrm{R} 0)$.

With 7 patients being lost by early death or incomplete follow-up, 122 patients were assessable for late treatmentrelated toxicity (table 3). Of 86 patients who had not received a feeding tube before or during treatment, $12 \mathrm{pa}$ tients (14\%) developed a late tube-dependent dysphagia. Repeated balloon dilatation or stenting was necessary in 33 patients (27\%). Tracheoesophageal fistulae occurred in 19 patients (16\%). Five fatal events (4\%) were undoubtedly related to treatment: 3 patients died of postoperative complications following surgery (anastomotic leakage) and 2 patients developed a fatal tracheoesophageal fistula (CRT group). The incidence of fatal events did not statistically differ between the two treatment groups $(\mathrm{p}=$ $0.66)$.

\section{Survival and Tumor Control}

The median follow-up time for patients alive was 3 years (36.1 months, range 5.6-124.3). On intent-to-treat analysis of all patients, the median, 2- and 5-year OS probability was 17.6 months (95\% confidence interval 13.0-22.0), 42 and $24 \%$, respectively. The 2 - and 5 -year LRC rates were 56 and $50 \%$, respectively, and the actuarial DC rates reached 67 and 52\%, respectively.

Comparing the CRT and C-CRT/S groups, there was no significant difference in terms of OS (2-year OS 39.1 vs. $45.1 \% ; \mathrm{p}=0.89$ ) (fig. 1a) and DC rates (2-year DC 71.2 vs. $62.4 \% ; \mathrm{p}=0.091$ ). However, patients in the CRT group 
Table 2. Treatment details

\begin{tabular}{|c|c|c|c|c|}
\hline & $\begin{array}{l}\text { CRT } \\
(\mathrm{n}=78)\end{array}$ & $\begin{array}{l}\text { C-CRT/S } \\
(\mathrm{n}=51)\end{array}$ & $\begin{array}{l}\text { Entire cohort } \\
(\mathrm{n}=129)\end{array}$ & $\mathrm{p}$ \\
\hline \multicolumn{5}{|l|}{ Surgery } \\
\hline None & $75(96)$ & $32(63)$ & $107(83)$ & \\
\hline Preceding CRT & $3(4)$ & & $3(2)$ & \\
\hline Following C-CRT & & $19(37)$ & $19(15)$ & $<0.001$ \\
\hline Median RT dose, Gy & $60[50-72]$ & $40[30-70]$ & $60[30-72]$ & $<0.001$ \\
\hline \multicolumn{5}{|l|}{ RT dose } \\
\hline$<50 \mathrm{~Gy}$ & & $28(55)$ & $28(22)$ & $<0.001$ \\
\hline$\geq 50 \mathrm{~Gy}$ & $78(100)$ & $23(45)$ & $101(78)$ & \\
\hline$<60 \mathrm{~Gy}$ & $32(41)$ & $30(59)$ & $62(48)$ & 0.07 \\
\hline$\geq 60 \mathrm{~Gy}$ & $46(59)$ & $21(41)$ & $67(52)$ & \\
\hline \multicolumn{5}{|l|}{ RT technique } \\
\hline IMRT & $22(28)$ & $1(2)$ & $23(18)$ & $<0.001$ \\
\hline 3D conformal & $56(72)$ & $50(98)$ & $106(82)$ & \\
\hline Median PTV, ml & $842[240-2,212]$ & 706 [334-1,529] & 788 [240-2,212] & \\
\hline \multicolumn{5}{|l|}{ Inductive $\mathrm{CT}$} \\
\hline Yes & $8(10)$ & $51(100)$ & $59(46)$ & $<0.001$ \\
\hline No & $70(90)$ & & $70(54)$ & \\
\hline \multicolumn{5}{|l|}{ Adherence to CT } \\
\hline $100 \%$ & $47(60)$ & $39(76)$ & $86(67)$ & 0.06 \\
\hline$<100 \%$ & $31(40)$ & $12(24)$ & $43(33)$ & \\
\hline$\geq$ two thirds & $57(73)$ & $49(96)$ & $106(82)$ & 0.01 \\
\hline$<$ two thirds & $21(27)$ & $2(4)$ & $23(18)$ & \\
\hline
\end{tabular}

Figures in parentheses are percentages; figures in brackets are ranges. IMRT = Intensity-modulated radiotherapy; PTV = planning target volume.

Table 3. Acute and late toxicity

\begin{tabular}{|c|c|c|c|c|}
\hline Acute toxicity & CRT $(\mathrm{n}=78)$ & C-CRT $(\mathrm{n}=51)$ & C-CRT/S $(\mathrm{n}=51)$ & $\mathrm{p}$ \\
\hline Hematological grade $3 / 4$ & $6(7)$ & $7(14)$ & $10(20)$ & $<0.001$ \\
\hline \multicolumn{5}{|l|}{ Non-hematological } \\
\hline Cardiovascular (arrhythmia/general) grade 5 & $2(3)$ & & & \\
\hline Tracheoesophageal fistula/bleeding grade 5 & $1(1)$ & & & \\
\hline Anastomotic leakage/aspiration pneumonia grade 5 & & $3(6)$ & & \\
\hline \multicolumn{5}{|l|}{ Acute dysphagia } \\
\hline Pre-existing gastrostomy dependency ${ }^{1}$ & $21(27)$ & $5(10)$ & & 0.024 \\
\hline Esophagitis requiring gastrostomy during treatment ${ }^{2}$ & $11 / 57(19)$ & $4 / 46(9)$ & $2 / 46(4)$ & 0.19 \\
\hline Late toxicity & $\operatorname{CRT}(\mathrm{n}=73)$ & C-CRT $(n=49)$ & C-CRT/S $(n=49)$ & $\mathrm{p}$ \\
\hline Late tracheoesophageal fistula & $8(10)$ & $9(18)$ & $2(4)$ & 0.077 \\
\hline Late tracheoesophageal fistula/bleeding grade 5 & $2(3)$ & & & \\
\hline \multicolumn{5}{|l|}{ Chronic dysphagia } \\
\hline Esophageal stricture requiring dilatation/stenting & $18(25)$ & $12(24)$ & $3(6)$ & 0.41 \\
\hline Esophageal stricture requiring late gastrostomy ${ }^{2}$ & $9 / 46(20)$ & $2 / 40(5)$ & $1 / 40(3)$ & 0.13 \\
\hline
\end{tabular}

Figures in parentheses are percentages.

${ }^{1}$ Indicating patients who needed to supplement most of their diet with gastrostomy tube feedings before treatment.

2 Percentages refer to patients at risk. 

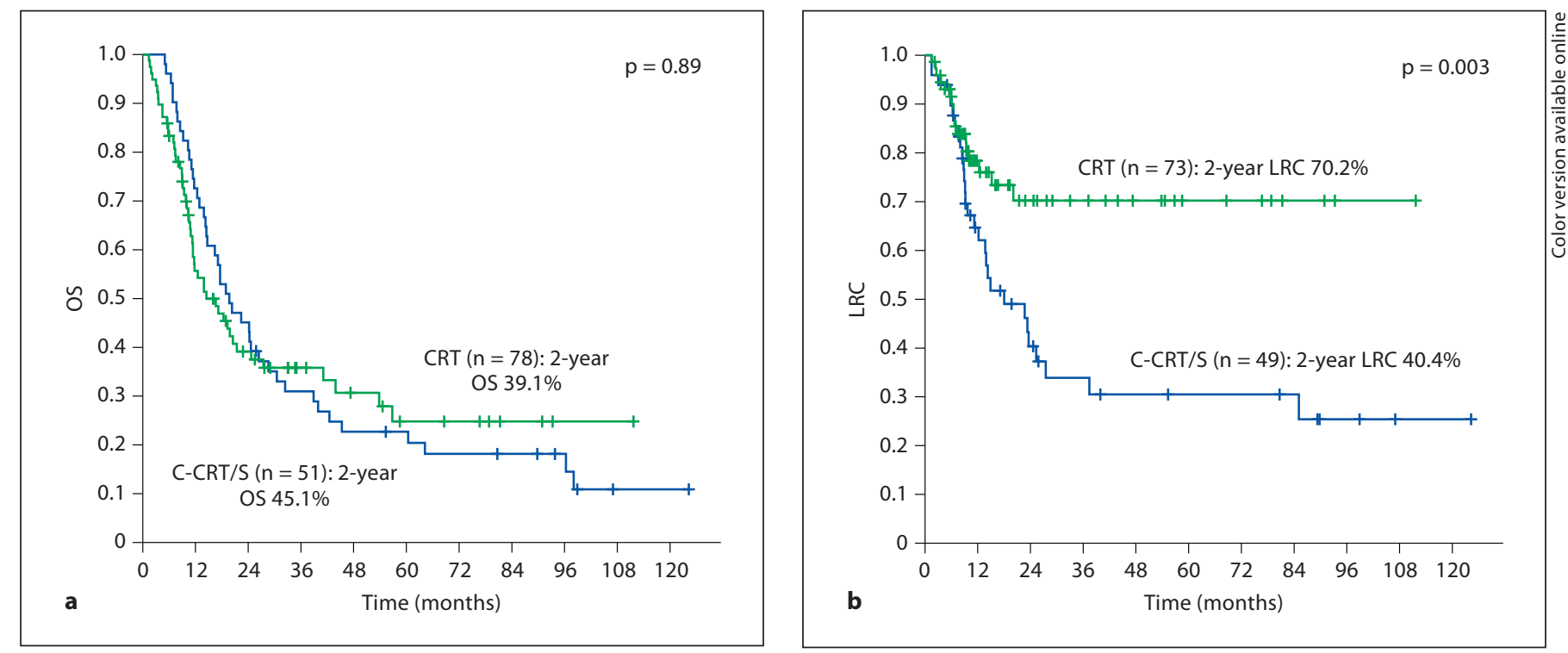

Fig. 1. Kaplan-Meier curves indicating OS (a) and LRC (b) stratified for the CRT and the C-CRT/S group ( $\mathrm{p}$ values determined by log-rank test).
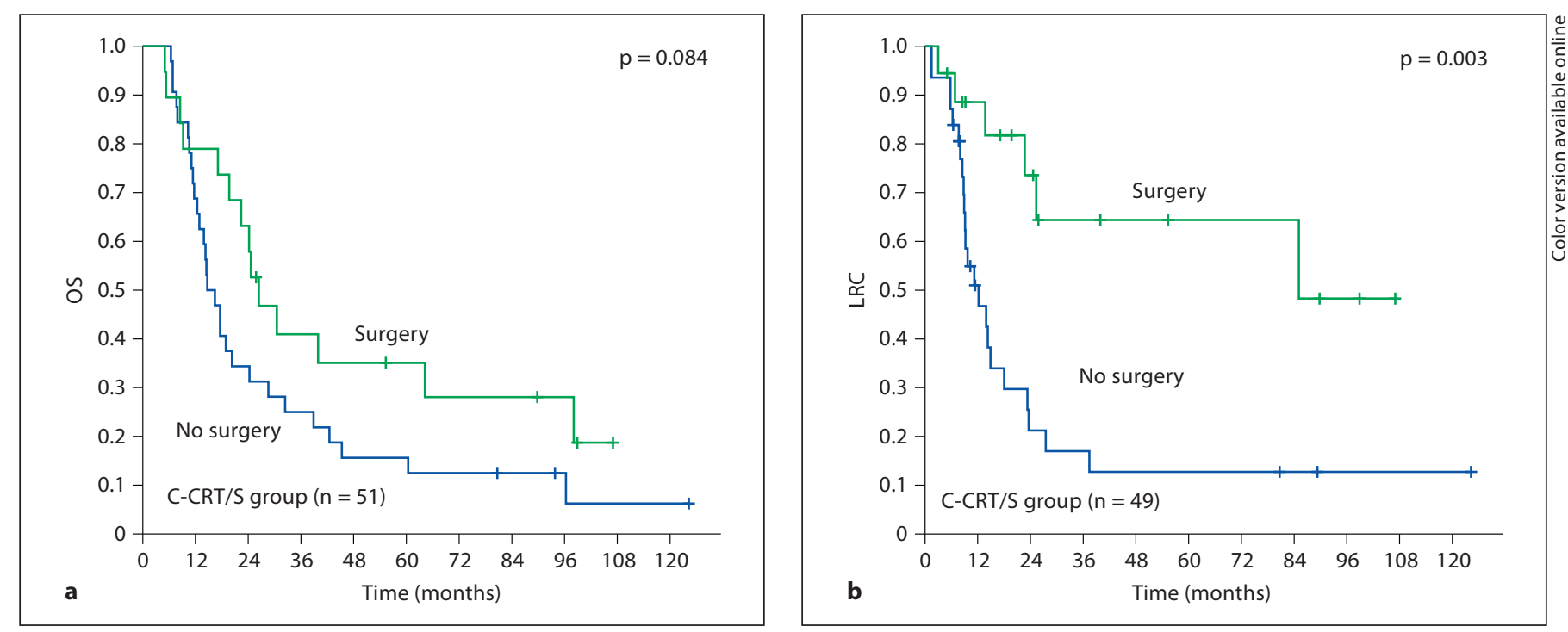

Fig. 2. Kaplan-Meier curves indicating OS (a) and LRC (b) in the C-CRT/S group stratified by surgery (p values determined by log-rank test).

showed significantly better LRC rates (2-year LRC 70.2 vs. $40.4 \% ; \mathrm{p}=0.003$ ) (fig. $1 \mathrm{~b}$ ). In the $\mathrm{C}-\mathrm{CRT} / \mathrm{S}$ group, the inclusion of surgery led to significantly improved LRC rates (2-year LRC with and without surgery 73.6 vs. $21.2 \%$, respectively; $\mathrm{p}=0.003)$; however, this was translated only into a trend towards improved OS (2-year OS 63.2 vs. $34.4 \% ; \mathrm{p}=0.084$ ) (fig. 2). Comparing the surgically re- sected patients of the C-CRT/S group with all other patients, a benefit was detectable for both OS and LRC, respectively, but this did not reach statistical significance (2-year OS 63.2 vs. $37.5 \%, p=0.18$; 2 -year LRC 73.6 vs. $52.0 \%, \mathrm{p}=0.27$ ).

In the CRT group, patients with T4 tumors or M1a stage showed pronouncedly poor LRC and OS rates (2- 

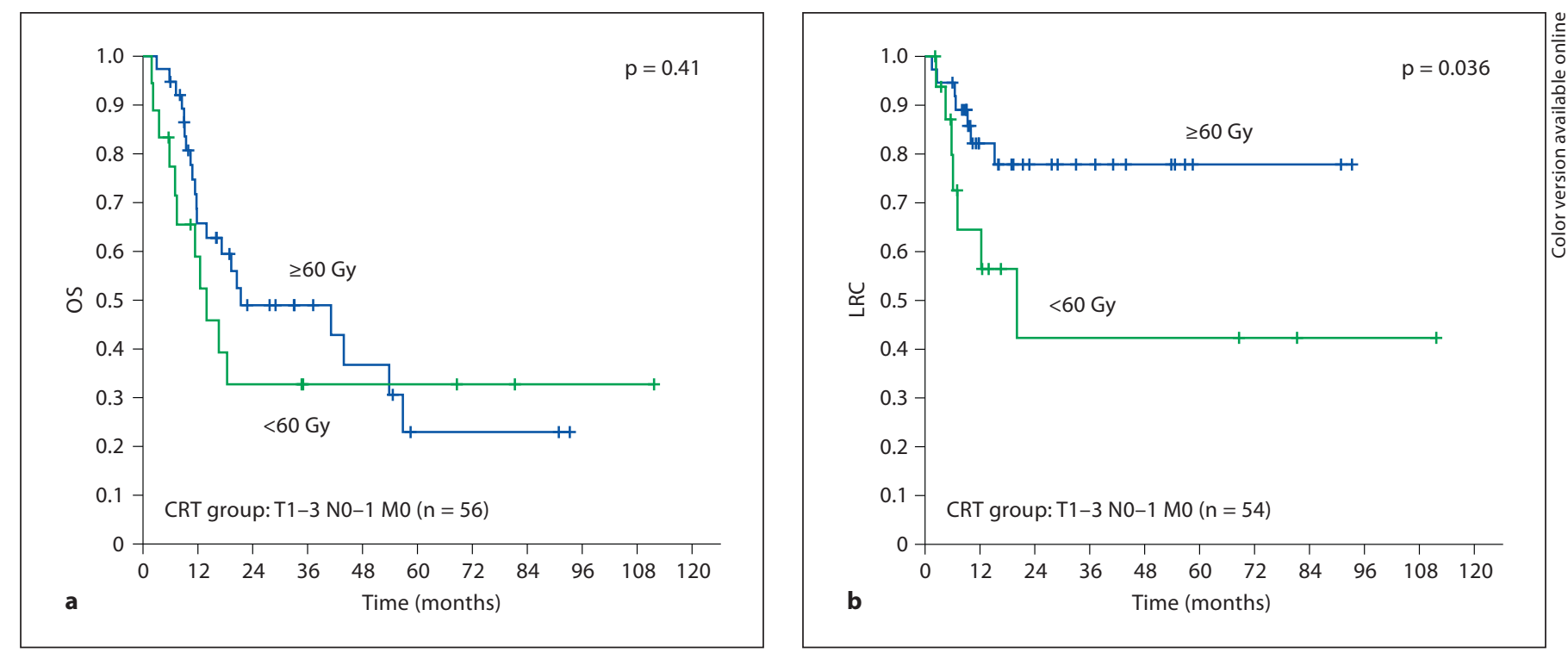

Fig. 3. Kaplan-Meier curves indicating OS (a) and LRC (b) in the T1-3 N0-1 M0 subgroup of the CRT group stratified by RT doses $<60.0$ and $\geq 60.0$ Gy (p values determined by log-rank test).

year OS T1-3 vs. T4 43.6 vs. 13.3\%; $\mathrm{p}=0.003)$. Accordingly, when excluding those patients, 43.9 and $27.4 \% 2$ and 5-year OS rates were reached in the T1-3 N0-1 M0 subgroup, respectively. With regard to RT doses, all patients who received $\geq 60$ Gy had better OS and LRC rates than those with $<60 \mathrm{~Gy}$, without reaching statistical significance ( $\mathrm{p}=0.32$ vs. 0.31 , respectively). A significant improvement in LRC rates by higher RT doses was only detectable in the T1-3 N0-1 M0 subgroup (2-year LRC 77.8 vs. $42.3 \%$; $\mathrm{p}=0.036$ ). However, again, this was not translated into improved OS (2-year OS 49.0 vs. $32.7 \%$; $\mathrm{p}=0.41)$ (fig. 3).

\section{Treatment Outcome and Prognostic Factors}

One hundred and twenty-four of 129 patients (92\%) were assessable for treatment response. The overall response rate (complete response plus partial response) was $77 \%$, with almost equal portions of patients achieving complete and partial response, respectively. At the time of the present analysis, 93 patients of the entire collective had died (64\% of the CRT group and $84 \%$ of the C-CRT/S group). Information on tumor control shortly before death was available in 90 patients. The majority $(81 \%)$ had died of locoregional or distant tumor progression with a significantly higher incidence of both locoregional and distant relapses in the C-CRT/S group compared to the CRT group (locoregional relapse 59 vs. $23 \%$, p < 0.001 ; distant progression 45 vs. $23 \%, \mathrm{p}=0.017$ ).
To derive conclusions specific to either CRT or CCRT/S, the impact of tumor- and treatment-related factors was evaluated separately for both treatment groups. In CRT patients, the univariate analysis showed the following covariates to be significantly prognostic of OS: tumor grading, $\mathrm{T}$ category (T1-3 vs. T4), nodal status, adherence to chemotherapy, and tumor response. Statistical significance was maintained multivariately except for the nodal status (table 4). In the C-CRT/S group, the tumor response was the only statistically significant factor, with surgery reaching just borderline significance $(\mathrm{p}=0.09)$. Regarding the influence of different RT doses ( $<60$ vs. $\geq 60$ and $<50$ vs. $\geq 50$ Gy in the CRT and C-CRT/S group, respectively), unequivocal effects were not detectable.

\section{Discussion}

With a 2 - and 5-year OS of 42 and $24 \%$, respectively, the survival outcome of this unselected population is in line with results yielded by large randomized trials on definitive CRT or trimodality treatment $[1,2,7,8]$. In view of the high proportion of advanced disease $(87 \%$ T3/4 tumors) and positive lymph nodes (79\%), this result is remarkable. In fact, the baseline characteristics of our patients were poorer than reported by other institutional series $[10-12,14]$. With respect to our CRT group, the OS and LRC rates are better than those achieved in the ran- 
Table 4. Prognostic factors on OS (CRT group)

\begin{tabular}{|c|c|c|c|c|}
\hline & \multicolumn{2}{|c|}{ Univariate analysis } & \multicolumn{2}{|c|}{ Multivariate analysis } \\
\hline & unadjusted HR & $\mathrm{p}$ & adjusted HR & $\mathrm{p}$ \\
\hline \multicolumn{5}{|l|}{ Age } \\
\hline$\leq 60$ versus $>60$ years & $1.08(0.62-1.9)$ & 0.78 & & \\
\hline \multicolumn{5}{|l|}{ Gender } \\
\hline Male versus female & $0.95(0.43-2.11)$ & 0.9 & & \\
\hline \multicolumn{5}{|l|}{ Histology } \\
\hline AC versus SCC & $0.44(0.19-1.03)$ & 0.059 & & \\
\hline \multicolumn{5}{|l|}{ Grading } \\
\hline G1/2 versus $G 3$ & $2.74(1.3-5.74)$ & 0.008 & $2.98(1.24-7.17)$ & 0.015 \\
\hline \multicolumn{5}{|l|}{ Tumor stage } \\
\hline $\mathrm{T} 1-2$ versus $\mathrm{T} 3$ & $0.32(0.1-1.06)$ & 0.062 & & \\
\hline $\mathrm{T} 1-3$ versus $\mathrm{T} 4$ & $0.4(0.22-0.78)$ & 0.005 & $0.33(0.14-0.8)$ & 0.014 \\
\hline \multicolumn{5}{|l|}{ Nodal status } \\
\hline N0 versus N1 & $0.43(0.19-0.95)$ & 0.036 & $0.38(0.12-1.23)$ & 0.11 \\
\hline \multicolumn{5}{|l|}{ RT dose } \\
\hline$\geq 60$ versus $<60 \mathrm{~Gy}$ & $0.76(0.43-1.32)$ & 0.324 & & \\
\hline \multicolumn{5}{|l|}{ Adherence to CT } \\
\hline$<100$ versus $100 \%$ & $2.78(1.58-4.83)$ & $<0.001$ & $3.48(1.11-10.93)$ & 0.033 \\
\hline$<$ two thirds versus $\geq$ two thirds & $1.89(1.04-3.43)$ & 0.037 & $0.42(0.13-1.34)$ & 0.143 \\
\hline \multicolumn{5}{|l|}{ Response } \\
\hline Less than $\mathrm{PR}$ versus $\mathrm{PR} / \mathrm{CR}$ & $3.0(1.56-5.8)$ & 0.001 & $1.13(0.41-3.11)$ & 0.82 \\
\hline Less than $\mathrm{CR}$ versus $\mathrm{CR}$ & $7.09(3.25-15.5)$ & $<0.001$ & $5.0(1.83-13.69)$ & 0.002 \\
\hline
\end{tabular}

Figures in parentheses are 95\% confidence intervals. $\mathrm{AC}=$ Adenocarcinoma; $\mathrm{SCC}=$ squamous cell carcinoma; $\mathrm{PR}=$ partial remission; $\mathrm{CR}=$ complete remission; $\mathrm{HR}=$ hazard ratio ( $>1$ indicative of worse survival).

domized and non-randomized part of the RTOG 8501 study [2]. This difference is further extended if one confines the analysis to the RTOG 8501 analog T1-3 N0-1 M0 patient subgroup which reached a durable 2-year LRC rate of $68 \%$ corresponding to a 2 - and 5 -year OS of 44 and $27 \%$, respectively. Thus, the present review reports a successful translation of phase III evidence into daily clinical practice.

The high rate of adherence to protocol may have influenced the positive outcome of definitive CRT. In fact, full completion of therapy is an important endpoint for patients with esophageal cancer who often interrupt treatment due to toxicity and a worsening performance status. Accordingly, in the RTOG 8501 trial, 7\% of patients did not receive full RT doses, and only $54 \%$ of patients completed all four cycles of chemotherapy [1]. In contrast, we here report complete adherence to RT, with $73 \%$ of patients having tolerated more than two thirds of chemotherapy.

Regarding the impact of escalated RT doses, we found an unequivocal effect only on LRC in the T1-3 N0-1 M0 subgroup (CRT collective). Apart from statistical reasons due to the small sample size, this result most probably stems from the poor outcome of patients with T4 tumors irrespective of RT doses and treatment schedule. In fact, a dose-response relationship $>50$ Gy has not been confirmed prospectively in esophageal cancer [6], and even retrospective studies are sparse. Institutional series reporting on a dose-response relationship predominantly concern the dose range of 30.0-50.0 Gy [15]. Information on doses $>50.0$ Gy is mostly derived from series on radiotherapy alone or on heterogeneously designed CRT [1418]. Recently, RT doses $>54.0$ Gy have been multivariately identified to impact OS in an unselected study population subjected to definitive CRT mainly based on mitomycin C [14]. However, in the absence of more detailed data on LRC and DC as well as on treatment-related toxicity, the issue of RT dose escalation >50 Gy needs further investigation. To conclude, although affected by all the methodological drawbacks of a retrospective institutional study, our analysis firstly confirms improved LRC rates by escalated RT doses $>50.0$ Gy in the context of definitive CRT strictly analogized to the RTOG 8501 trial. 
As to trimodality treatment, randomized data have shown the positive impact of surgery on LRC in esophageal cancer without translation into improved OS $[7,8]$. In the present analysis, these results have been confirmed by the comparison of patients treated surgically in the CCRT/S group and those treated in analogy to the RTOG 8501 concept. Within our C-CRT/S cohort, surgery significantly improved the LRC rates; however, this could not compensate for the pronouncedly poor results of CCRT/S patients who were not operated and stopped treatment after insufficient RT doses (median 40.0 Gy). In contrast, inferior LRC and DC rates within the C-CRT/S group did not lead to inferior OS rates when compared to patients subjected to CRT; one possible explanation would be the higher amount of non-tumor-related deaths in the CRT group. However, beyond doubt, a selection bias resulting from the non-randomized allocation of patients to the two individually adapted treatment concepts limits final statements.
CRT performed in accordance to RTOG 8501 (RT dose range 59.4-66.6 Gy) has been compared to CRT plus surgery (RT dose range 41.4-50.4 Gy) in one other single analysis [12]. Further available reports are characterized by differing radiotherapy schedules $[10,16]$ or variable chemotherapy regimens with lower cumulative cisplatin doses or even without cisplatin $[11,14,16]$. In conclusion, the successful translation of LRC benefits into improved OS is a challenge regardless of whether LRC is achieved by surgery or high-dose CRT. In this regard, the optimal management of treatment-related toxicities and individual comorbid factors is of high importance.

\section{Disclosure Statement}

There are no conflicts of interest.

\section{References}

1 Herskovic A, Martz K, al-Sarraf M, et al: Combined chemotherapy and radiotherapy compared with radiotherapy alone in patients with cancer of the esophagus. N Engl J Med 1992;326:1593-1598.

2 Cooper JS, Guo MD, Herskovic A, et al: Chemoradiotherapy of locally advanced esophageal cancer: long-term follow-up of a prospective randomized trial (RTOG 85-01). Radiation Therapy Oncology Group. JAMA 1999;281:1623-1627.

3 al-Sarraf M, Martz K, Herskovic A, et al: Progress report of combined chemoradiotherapy versus radiotherapy alone in patients with esophageal cancer: an intergroup study. J Clin Oncol 1997;15:277-284.

4 Berger B, Belka C: Evidence-based radiation oncology: esophagus. Radiother Oncol 2009; 92:276-290.

5 Malthaner RA, Wong RK, Rumble RB, Zuraw L: Neoadjuvant or adjuvant therapy for resectable esophageal cancer: a systematic review and meta-analysis. BMC Med 2004;2:35.

6 Minsky BD, Pajak TF, Ginsberg RJ, et al: INT 0123 (Radiation Therapy Oncology Group 94-05) phase III trial of combined-modality therapy for esophageal cancer: high-dose versus standard-dose radiation therapy. J Clin Oncol 2002;20:1167-1174.
7 Bedenne L, Michel P, Bouche O, et al: Chemoradiation followed by surgery compared with chemoradiation alone in squamous cancer of the esophagus: FFCD 9102. J Clin Oncol 2007;25:1160-1168.

8 Stahl M, Stuschke M, Lehmann N, et al: Chemoradiation with and without surgery in patients with locally advanced squamous cell carcinoma of the esophagus. J Clin Oncol 2005;23:2310-2317.

9 Adams R, Morgan M, Mukherjee S, et al: A prospective comparison of multidisciplinary treatment of esophageal cancer with curative intent in a UK cancer network. Eur J Surg Oncol 2007;33:307-313.

10 Delcambre C, Jacob JH, Pottier D, et al: Localized squamous-cell cancer of the esophagus: retrospective analysis of three treatment schedules. Radiother Oncol 2001;59:195201.

11 Denham JW, Burmeister BH, Lamb DS, et al: Factors influencing outcome following radio-chemotherapy for esophageal cancer. The Trans Tasman Radiation Oncology Group (TROG). Radiother Oncol 1996;40: 31-43.

12 Rades D, Schulte R, Yekebas EF, et al: Radio(chemo)therapy plus resection versus radio(chemo)therapy alone for the treatment of stage III esophageal cancer. Strahlenther Onkol 2007;183:10-16.
13 Tepper J, Krasna MJ, Niedzwiecki D, et al: Phase III trial of trimodality therapy with cisplatin, fluorouracil, radiotherapy, and surgery compared with surgery alone for esophageal cancer: CALGB 9781. J Clin Oncol 2008;26:1086-1092.

14 Wolf M, Zehentmayr F, Niyazi M, et al: Long-term outcome of mitomycin C- and 5-FU-based primary radiochemotherapy for esophageal cancer. Strahlenther Onkol 2010; 186:374-381.

15 Zhang Z, Liao Z, Jin J, et al: Dose-response relationship in locoregional control for patients with stage II-III esophageal cancer treated with concurrent chemotherapy and radiotherapy. Int J Radiat Oncol Biol Phys 2005;61:656-664.

16 Seung SK, Smith JW 2nd, Ross HJ: Selective dose escalation of chemoradiotherapy for locally advanced esophageal cancer. Dis Esophagus 2008;21:589-595

17 Shi XH, Yao W, Liu T: Late course accelerated fractionation in radiotherapy of esophageal carcinoma. Radiother Oncol 1999;51:21-26.

18 Mizumoto M, Sugahara S, Nakayama H, et al: Clinical results of proton-beam therapy for locoregionally advanced esophageal cancer. Strahlenther Onkol 2010;186:482-488. 